\title{
Rare Endoscopic Manifestation of Pancreatic Adenocarcinoma
}

\author{
Haritha Chelimilla Ariyo Ihimoyan Masooma Niazi \\ Anil Dev \\ Division of Gastroenterology, Bronx-Lebanon Hospital Center, Bronx, N.Y., USA
}

\section{Key Words}

Pancreatic adenocarcinoma - Gastric ulcer - Gastrointestinal metastasis - Endoscopic evaluation

\begin{abstract}
Gastric ulcer secondary to direct invasion from pancreatic adenocarcinoma is rare. Metastases to the stomach have been commonly reported with melanoma and with primary tumors of the breast, lung, ovary, liver, colon and testis. We report a patient who presented with epigastric pain and in whom subsequently upper endoscopy showed a malignant gastric ulcer secondary to direct invasion from pancreatic adenocarcinoma of the body. An 81-year-old female presented to our hospital with epigastric pain and subsequently underwent endoscopy with endoscopic ultrasound for evaluation of a pancreatic body mass. She had a large gastric ulcer in the fundus which was in direct continuity with the pancreatic mass. Pathology from biopsy of the ulcer revealed invasive well-to-moderately-differentiated adenocarcinoma, and immunohistochemical stains were strongly positive for CA19-9, CK7, CK19 and carcinoembryonic antigen. These findings were consistent with a histopathological diagnosis of metastatic carcinoma of the pancreas. Patients with gastrointestinal metastases usually have advanced malignancy with poor prognosis. Endoscopic evaluation with adequate biopsies should be performed for symptomatic patients.
\end{abstract}

\section{Introduction}

Gastric involvement by extragastric neoplasm is a rare occurrence. The reported incidence of gastric metastases from prior autopsy series was $0.2-1.7 \%[1,2]$. The most common primary malignancies are lung and breast cancer and malignant melanoma. Pancreatic adenocarcinoma presenting as a malignant gastric ulcer is uncommon. Gastric involvement may occur by direct invasion, hematogenous or lymphatic spread or intraoperative seeding. These may be diagnosed at variable intervals from primary tumor recognition. Gastric metastases has been reported to 
occur up to 1 year after resection of pancreatic cancer [3]. These lesions may rarely be the first manifestation of the disease and their recognition is important in order to correctly identify the primary neoplasm. They may have variable patterns of appearance on endoscopic and radiological exam. These include solitary or multiple polypoid masses which may ulcerate, constricting infiltrative pattern like linitis plastica [2]. Infiltrating pattern is seen in about $50 \%$ of breast cancers, while melanomas most commonly present with multiple small ulcerating masses [1, 4]. Although there is no specific symptom associated with them, gastrointestinal bleeding including occult gastrointestinal bleed and abdominal pain are the most common [5]. Usually such patients have a poor prognosis due to late occurrence. Overall 5-year survival is dismal at $5 \%$ [6]. The most frequent sites of metastasis for carcinoma of the pancreas are the lymph nodes, lung, liver, adrenal glands, kidney and bone [7]. There are few case reports of soft tissue metastases from pancreatic cancer [8]. We here report a rare endoscopic manifestation of pancreatic adenocarcinoma as a malignant gastric ulcer.

\section{Case Report}

An 81-year-old woman was admitted initially with epigastric pain of 3 days duration. She described the pain as sharp, radiating to the back and continuous. She denied any nausea, vomiting or diarrhea. She had chronic constipation. She had lost about $12 \%$ of her body weight over the last 2 months. Her prior medical history was significant for hypertension, diabetes, peripheral vascular disease, hyperlipidemia, cerebrovascular accident, paroxysmal atrial fibrillation, congestive heart failure and deep vein thrombosis status post inferior vena cava filter. Her home medications included hydralazine, enalapril, Lantus, simvastatin, Colace, metoprolol, ferrous sulfate, vitamin B12 tablets, calcium carbonate, Actos and isosorbide. Her surgical history included left above-knee amputation. She denied any history of smoking or alcohol use or recreational drug use. There was no family history of gastrointestinal-related malignancies. Her last colonoscopy 10 years before had been unremarkable.

Physical examination revealed an obese woman with a body mass index of 31 . Her abdomen was soft with epigastric tenderness. No other abnormal findings were found. Laboratory data revealed hemoglobin of $9.6 \mathrm{mg} / \mathrm{dl}$, white blood cell count of $6,000 / \mu \mathrm{l}$ and serum creatinine of $0.7 \mathrm{mg} / \mathrm{dl}$. Her alanine transferase was $8 \mathrm{mg} / \mathrm{dl}$ and aspartate transferase was $14 \mathrm{mg} / \mathrm{dl}$; alkaline phosphatase, bilirubin and albumin were normal. Her coagulation profile was within normal limits. Her lipase was normal. Ferritin was $20 \mathrm{mg} / \mathrm{dl}$. Stool guaiac was positive. CT scan of the abdomen (fig. 1) showed a $3.5 \times 4.0 \mathrm{~cm}$ hypodense, nonenhancing mass within the body of the pancreas with dilatation of the pancreatic duct and atrophy of the pancreatic parenchyma distal to the mass. The mass was completely encasing the splenic artery and partially the common hepatic artery. Additionally, its margins from the posterior gastric wall could not be discerned (fig. 1). Her serum CA19-9 was $>1,000 \mathrm{U} / \mathrm{ml}$. Subsequently upper endoscopic ultrasound (fig. 2) was performed which revealed an irregular hypoechoic mass $3.7 \times 2.5 \mathrm{~cm}$ in the pancreatic body with evidence of invasion of the gastric wall. A large cratered friable ulcer in the gastric fundus (fig. 3 ) was seen. Biopsies taken from the ulcer showed well-to-moderately-differentiated invasive adenocarcinoma (fig. 4), and immunohistochemical stains were strongly positive for CA19-9 (fig. 5), CK7, CK19 and carcinoembryonic antigen (CEA), which favored metastatic carcinoma of the pancreas. Surgical evaluation was done, but due to the mass completely encasing the splenic artery and partially the common hepatic artery as well as not being able to discern the posterior gastric wall from the mass, it was deemed unresectable. The patient was evaluated by oncology, the cancer was considered locally advanced and treatment options including chemotherapy with radiation versus palliative care were discussed. The patient wanted comfort measures and was enlisted with palliative care services. She died 2 months later. 


\section{Discussion}

Endoscopic diagnosis of gastric metastases arising from pancreatic adenocarcinoma is uncommon. Metastatic disease to the stomach can occur with melanoma and with primary tumors of the breast, lung, ovary, liver, colon and testis, with breast cancer being the most common [9]. Other rare malignant tumors that can involve the stomach are Kaposi's sarcoma, myenteric schwannoma, glomus tumor, small cell carcinoma and parietal cell carcinoma. Most of the metastases are diagnosed at autopsy.

Metastases in the gastrointestinal tract commonly presents as a single lesion [10]. Gastric involvement may occur by different mechanisms, namely by direct invasion, hematogenous spread, lymphatic metastases, intramural or intraluminal dissemination or intraoperative seeding [11]. In our patient, endoscopic ultrasound revealed a pancreatic body mass invading the gastric wall which was seen endoscopically as a large gastric fundic ulcer in direct continuity, and this was confirmed by pathology.

The most common clinical presentations of gastrointestinal metastases are acute upper gastrointestinal bleeding and anemia [12]. There may be gradual blood loss with resultant iron deficiency anemia, which may be the only manifestation of gastric involvement. Hence anemia in such patients should be worked up with stool occult blood test. Other symptoms include weight loss, anorexia, abdominal discomfort, nausea and vomiting [2]. Endoscopically, gastrointestinal metastases present as submucosal tumors and polypoid masses, with either erosion or ulceration and infiltrating pattern with linitis plastica $[10,12]$. Our patient presented with epigastric pain and anemia. Usually gastric metastases are diagnosed in the late phase of the disease but can be the earliest manifestation of metastatic disease. Death can result from rapid blood loss or perforation of the lesion with resultant peritonitis and hypovolemic shock [13].

Distal tumors of the pancreas may invade local structures such as the spleen, stomach, splenic flexure of the colon or left adrenal gland. In patients with advanced pancreatic cancer, metastases to the lymph nodes, liver and peritoneum are common, while involvement of the lung, pleura and bone is less common [7].

Endoscopy is useful in the evaluation of these lesions, especially when radiological studies are unrevealing. It may also help in monitoring the course of the disease while on treatment [14]. Diagnosis becomes difficult when the primary neoplasm is unknown at the time of presentation. Immunohistochemistry is often useful in differentiating primary sites of tumor origin when the histology is inconclusive. The common markers for mucin-producing tumors such as pancreatic adenocarcinoma are MUC1, MUC3, MUC4, CEA, CA19-9, DuPan 2 and CA125. These markers are more useful in distinguishing neoplastic from nonneoplastic ductal changes and in distinguishing ductal from acinar or neuroendocrine tumors [15].

In our patient, the immunohistochemical stains came positive for CA19-9, CK7, CK19 and CEA. The immunochemical staining characteristics along with the presence of a pancreatic mass with direct endosonographic invasion of the gastric wall favored the diagnosis of metastatic carcinoma of the pancreas.

Metastasis to the stomach from an extragastric neoplasm is an unusual event, identified in $<2 \%$ of cancer patients at autopsy. For accurate diagnosis of gastric 
metastases, a combination of good clinical history, imaging study and endoscopic examination along with histopathologic evaluation is necessary. The prognosis of patients with gastric metastases is usually poor, and gastric endoscopy with adequate biopsies plays an important role in the evaluation of these patients.

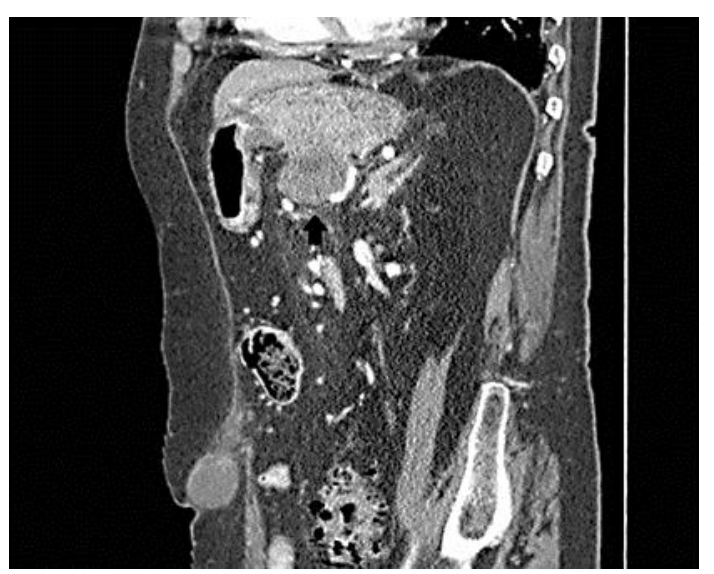

Fig. 1. CT scan of the abdomen with the arrow showing the pancreatic mass invading the gastric wall.

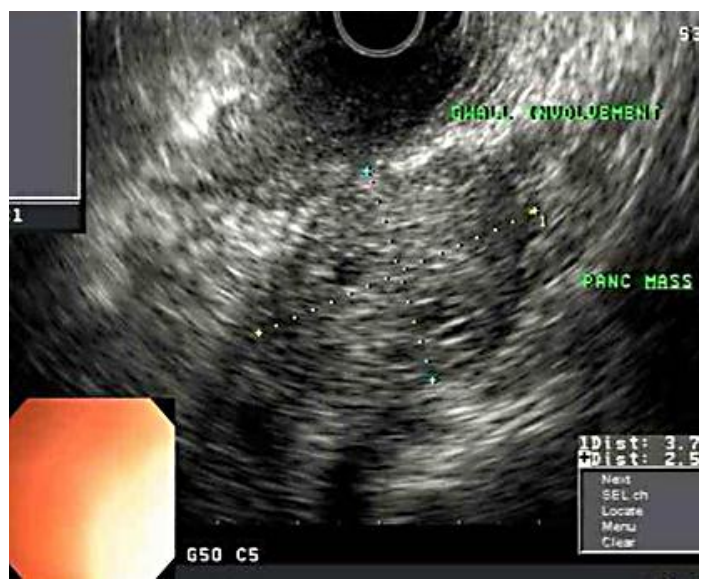

Fig. 2. Endoscopic ultrasound image of the pancreatic mass with gastric involvement. 


\begin{tabular}{r|l|l|l}
$\begin{array}{r}\text { Case Reports in } \\
\text { Gastroenterology }\end{array}$ & $\begin{array}{l}\text { Case Rep Gastroenterol 2012;6:496-501 } \\
\text { DOI: 10.1159/000341524 }\end{array}$ & $\begin{array}{l}\text { Published online: } \\
\text { July 24, 2012 }\end{array}$ & $\begin{array}{l}\text { @ 2012 S. Karger AG, Basel } \\
\text { ISSN 1662-0631 } \\
\text { www.karger.com/crg }\end{array}$ \\
\hline
\end{tabular}

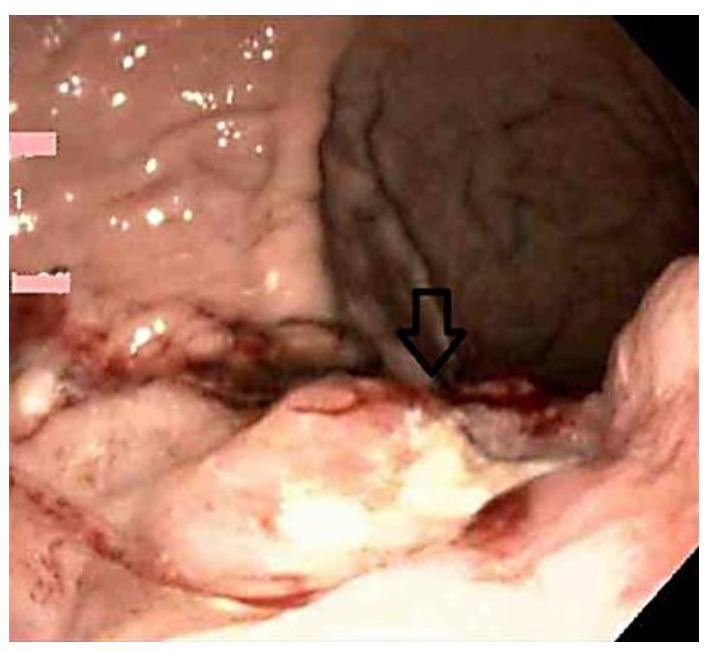

Fig. 3. Endoscopic view of the ulcer in the fundus of the stomach. The arrow points at the ulcer base.

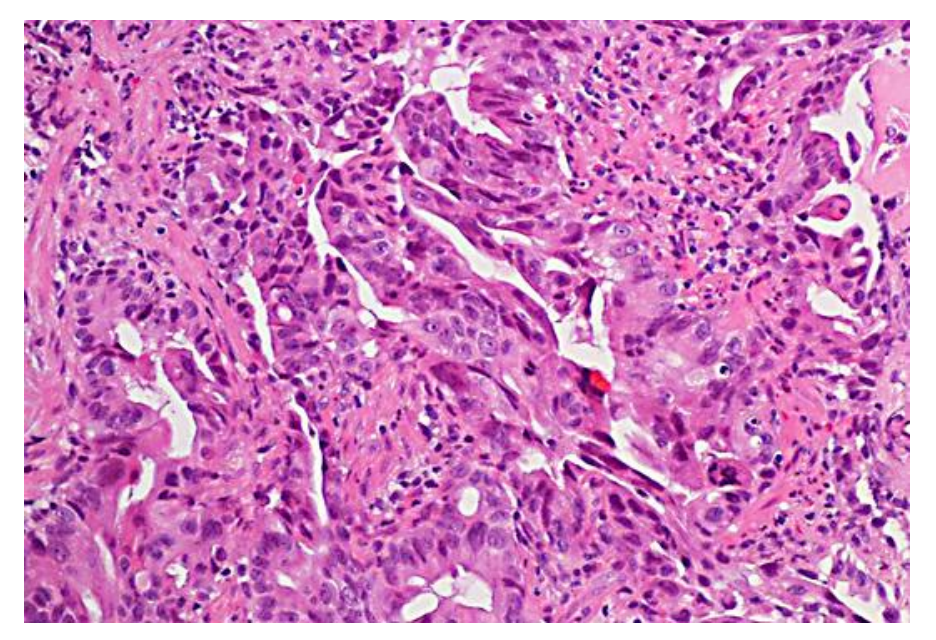

Fig. 4. H\&E stain of the gastric ulcer biopsy revealing well-to-moderately-differentiated adenocarcinoma (original magnification $\times 40$ ). 


\begin{tabular}{r|l|l|l}
$\begin{array}{r}\text { Case Reports in } \\
\text { Gastroenterology }\end{array}$ & $\begin{array}{l}\text { Case Rep Gastroenterol 2012;6:496-501 } \\
\text { DOI: 10.1159/000341524 }\end{array}$ & $\begin{array}{l}\text { Published online: } \\
\text { July 24, 2012 }\end{array}$ & $\begin{array}{l}\text { @ 2012 S. Karger AG, Basel } \\
\text { ISSN 1662-0631 } \\
\text { www.karger.com/crg }\end{array}$ \\
\hline
\end{tabular}

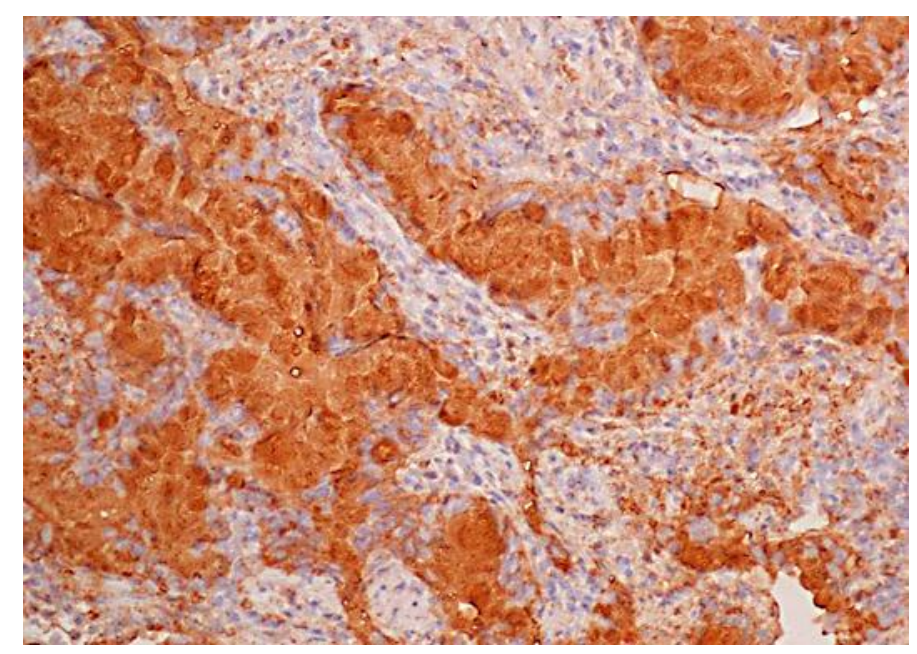

Fig. 5. Immunostaining with CA19-9 (original magnification $\times 40$ ).

\section{References}

1 Menuck LS, Amberg JR: Metastatic disease involving the stomach. Am J Dig Dis 1975;20:903-913.

-2 Green LK: Hematogenous metastases to the stomach. A review of 67 cases. Cancer 1990;62:1596-1600.

-3 Takamori H, Kanemitsu K, Tsuji T, Kusano S, Chikamoto A, Okuma T, Iyama K: Metastatic gastric tumor secondary to pancreatic adenocarcinoma. J Gastroenterol 2005;40:209-212.

4 Choi S, Sheehan F, Pickren J: Metastatic involvement of the stomach by breast cancer. Cancer 1964;17:791-797.

-5 Caramella E, Bruneton JN, Roux P, Aubanel D, Lecomte P: Metastases of the digestive tract. Report of 77 cases and review of the literature. Eur J Radiol 1983;3:331-338.

-6 Jemal A, Siegel R, Ward E, et al: Cancer statistics, 2009. CA Cancer J Clin 2009;59:225-249.

7 Solcia E, Capella C, Kloppel G: Tumors of the exocrine pancreas; in Rosai J, Sorbin L (eds): Atlas of Tumor Pathology: Tumors of the Pancreas. Washington, D.C., Armed Forces Institute of Pathology, 1997, pp 31-144.

8 Akasbi Y, Arifi S, El Idrissi M, Shimi M, Boutayeb F, El Mrini A, El Mesbahi O: Soft-tissue metastasis revealing a pancreatic adenocarcinoma: one case report and a review of literature. Pan Afr Med J 2012;11:32.

9 De Palma GD, Masone S, Rega M, Simeoli I, Donisi M, Addeo P, Iannone L, Pilone V, Persico G: Metastatic tumors to the stomach: clinical and endoscopic features. World J Gastroenterol 2006;12:7326-7328.

10 Oda I, Kondo H, Yamao T, Saito D, Ono H, Gotoda T, Yamaguchi H, Yoshida S, Shimoda T: Metastatic tumors to the stomach: analysis of 54 patients diagnosed at endoscopy and 347 autopsy cases. Endoscopy 2001;33:507-510.

11 Feczko PJ, Collins DD, Mezwa DG: Metastatic disease involving the gastrointestinal tract. Radiol Clin North Am 1993;31:1359-1373.

12 Hsu CC, Chen JJ, Changchien CS: Endoscopic features of metastatic tumors in the upper gastrointestinal tract. Endoscopy 1996;28:249-253.

13 Edwards R, Royle G: Metastatic carcinoma causing haematemesis. Br Med J 1975; 2:598.

14 Morini S, Bassi O, Colavolpe V: Malignant melanoma metastatic to the stomach: endoscopic diagnosis and findings. Endoscopy 1980;12:86-89.

15 Hruban RH, Pitman MB, Klimstra DS: Ductal adenocarcinoma; in: Atlas of Tumor Pathology: Tumors of the Pancreas. Washington, D.C., American Registry of Pathology, 2007, pp 111-164. 